\title{
LAS REGLAS DE LA ENTREVISTA INVESTIGATIVA VIDEOGRABADA Y EL DERECHO A LA PRUEBA PENAL. UNA PROPUESTA DESDE LA TEORÍA DE LOS CONFLICTOS NORMATIVOS
}

\author{
THE RULES OF THE VIDEO-RECORDED INVESTIGATIVE \\ INTERVIEW AND THE RIGHT TO CRIMINAL EVIDENCE. \\ A PROPOSAL FROM THE THEORY OF THE NORMATIVE \\ CONFLICTS
}

PABLO DURÁN LEIVA ***

\section{RESUMEN}

El trabajo es una propuesta de identificación y análisis de tres conflictos normativos o antinomias producidas en la aplicación de reglas contenidas en la ley de entrevista investigativa videograbada. Utilizando herramientas analíticas de la teoría de los conflictos normativos, se describirán antinomias en contextos concretos en los que un juez deberá decidir por la preminencia del principio del debido proceso, en su expresión derecho a la prueba, o la del respeto al interés superior del niño. Hecho el análisis, se ofrecen soluciones para preferir un principio u otro, una regla u otra, mediante la consideración

* Abogado. Licenciado en Cs. Jurídicas, Universidad de Chile. Magister en Derecho Público, Universidad Austral de Chile, Valdivia, Chile. Magister en Derecho, Mención Constitucionalismo y Derecho, Universidad Austral de Chile, Valdivia, Chile. Doctorando en Derecho, Universidad Austral de Chile, Valdivia, Chile. Correo electrónico: pabloduranleiva@gmail.com. ORCID: https://orcid. org/0000-0001-8083-1610.

** Este trabajo se enmarca en las actividades académicas impuestas por el programa de Doctorado Derecho, mención Constitucionalismo y Derecho, de la Universidad Austral de Chile. Agradezco a Sebastián Agüero San Juan, Daniela Accatino Scagliotti, Álvaro Núñez Vaquero, Víctor García Yzaguirre, Rodrigo Flores Luna y a los árbitros de esta publicación, por su lectura, comentarios y observaciones.

Trabajo recibido el 28 de agosto de 2020 y aceptado para su publicación el 2 de junio de 2021. 
de la edad de la víctima, la presencia de daño en ella, su revictimización, la reiteración de delitos motivo del proceso, u otras circunstancias concretas del caso.

Palabras clave: Entrevista Investigativa Videograbada; Interés Superior; Debido Proceso; Derecho a la Prueba; Antinomia; Teoría de la Ponderación.

\section{ABSTRACT}

The work is a proposal for the identification and analysis of three normative conflicts or antinomies produced in the application of rules contained in the videorecorder investigative interview law. Using analytical tools of the Normative Conflicts Theory, antinomies will be described in specific contexts in which the judge decides the preeminence of the principle of due process, in its expression right to proof, or that of respect for interest superior of the child. After the analysis, a solution is obtained to prefer one principle or another, one rule or another, by considering the age of the victim, the presence of emotional damage in, revictimization, the repetition of crimes that are the cause of the process, or other concrete circunstances.

Keywords: Video Recorded Investigative Interview; Superior Interest; Due process; Right to Evidence; Antinomy; Balancing Theory.

\section{INTRODUCCIÓN}

La entrada en vigencia en Chile de la Ley No21.057 (en adelante Ley de EIV) que regula la forma en la que se registra el testimonio de niños, niñas y adolescentes (NNA) en el contexto del proceso penal, abre nuevos puntos de interés para la teoría, la dogmática y la práctica jurídica. En particular, las reformas procedimentales respecto de la recepción de los primeros antecedentes del hecho denunciado, el registro mediante videograbación de la entrevista realizada al NNA por un funcionario especializado, tanto en la etapa investigativa, como en la judicial y el acceso directo a la prueba testimonial, generan inquietud entre los operadores, tanto respecto de eventuales tensiones normativas, como respecto de los cambios e impacto 
que tendrá esta reforma en la resolución de estos asuntos.

La Ley de EIV fue publicada el 20 de enero de 2018 y su vigencia es gradual, siguiendo la experiencia de la Reforma Procesal Penal, comenzando en regiones extremas para terminar en la Región Metropolitana.

El objeto de la ley es priorizar los derechos de los NNA y protegerlos de la victimización a la que están expuestos en el proceso penal. ${ }^{1}$ Este objeto obliga la modificación de ciertas prácticas sobre el acceso al testimonio del NNA, su registro y reproducción, respecto de delitos en los que, en muchos casos, no existe otra prueba de cargo para decidir sobre los hechos. Así, la pretensión del fiscal, el defensor o el imputado, puede ceder ante la pretendida protección y respeto al interés superior del niño. Será una decisión concreta del juez, la que resolverá en un caso determinado la preminencia de una norma por sobre otra, según pretendo ilustrar en las secciones siguientes. Se trata en uno u otro caso de un agente que estará ante un conflicto antinómico que deberá resolver.

Un conflicto antinómico se produce cuando dos normas establecen para el mismo supuesto de hecho dos soluciones o consecuencias jurídicas incompatibles. ${ }^{2}$ La existencia de antinomias en un conjunto de normas vuelve a dicho sistema inconsistente o incoherente, ya sea que estas se produzcan de forma abstracta del mero texto normativo o su sistema de fuentes o que se produzcan en concreto de la aplicación de las normas al caso en su contexto. Ahondaremos más adelante en estas distinciones.

Por tanto, en ese contexto, este texto es una propuesta sintética de identificación y análisis de tres conflictos normativos o antinomias identificadas a partir del texto de la Ley de EIV, un conflicto entre principios y dos conflictos entre reglas concretadas a partir de ellos. Intentaré evidenciar las antinomias que pudieren producirse en contextos fácticos determinados en los que el juez deberá resolver la preminencia de la norma relativa al principio del debido proceso, en su expresión derecho a la prueba, o aquella relativa al principio del respeto al interés superior del niño. Para este análisis utilizaré algunos elementos analíticos de la Teoría de la Ponderación, previa identificación, reformulación y categorización de las normas que, en el caso,

\footnotetext{
${ }^{1}$ Artículo 1 de la Ley №21.057 (2018) Que regula entrevistas grabadas en video y, otras medidas de resguardo a menores de edad, víctimas de delitos sexuales.

${ }^{2}$ Cfr. Guastini, Riccardo, Las Fuentes del Derecho. Fundamentos Teóricos, Raguel Editores, Lima, 2016, p.537.
} 
producen la antinomia.

Luego, como segunda línea de análisis propongo la utilización de otras dos normas extraídas de distintos enunciados contenidos en la misma Ley de EIV, para verificar el rendimiento de las categorías taxonómicas ofrecidas por la Teoría del Derecho en los conflictos producidos entre esas reglas. En este punto, recurriré a la propuesta analítica de Riccardo GUASTINI, para concretar las reglas que producen el conflicto al agente, a partir del principio del debido proceso.

Por tanto, no es esta una propuesta presentada desde la dogmática procesal penal, sino un ejercicio analítico desde la teoría de los conflictos normativos, cuya pretensión es ofrecer herramientas teóricas al operador del derecho que pueda verse sometido a una antinomia, aun cuando se trate de supuestos distintos a los que utilizaré. La teoría de los conflictos normativos resultará útil en la aplicación de los principios y reglas de la Ley de EIV.

II. EL CONFLICTO ENTRE EL DEBIDO PROCESO Y EL RESPETO DEL INTERÉS SUPERIOR DEL NIÑO, UN CONFLICTO ENTRE PRINCIPIOS O DIRECTRICES

\section{El debido proceso en general y derecho a la prueba en particular}

\subsection{Generalidades}

Para analizar el primer conflicto normativo referiré algunas generalidades en relación a las normas que, en el caso antinómico presentado, conflictúan al agente. La primera de esas normas es aquella relativa al debido proceso.

El debido proceso, a grandes rasgos, refiere al conjunto de requisitos que deben observarse en las instancias procesales a efectos de que las personas estén en condiciones de defender adecuadamente sus derechos ante cualquier acto del Estado que pueda afectarlos. ${ }^{3}$ En el Sistema Interamericano de Derechos Humanos, ${ }^{4}$ está consagrado en el artículo $8^{\circ}$ de la Convención

\footnotetext{
${ }^{3}$ Cfr. García, Sergio. "El debido proceso en la jurisprudencia de la Corte Interamericana de derechos humanos", en Tavolari, R. (coord.), Derecho Procesal Contemporáneo. Ponencias de las XII Jornadas Iberoamericanas de Derecho Procesal. Thomson Reuters - Punto Lex, Santiago, 2010, T. I, p. 16.

${ }^{4}$ Este derecho ha tenido especial atención en el Sistema Interamericano de Derechos Humanos, tanto en materias contenciosas como no contenciosas. Es así que la Corte Interamericana entre los años
} 
Americana y para su configuración se relaciona con otras normas del mismo cuerpo como la igualdad ante la ley y el derecho a la protección judicial. ${ }^{5}$

Cuando se hace referencia al debido proceso en la Constitución chilena, nos encontramos con una cláusula de contenido indeterminado que debe ser llenada por el operador del derecho, el legislador o por los tribunales de justicia. Aún sin expreso reconocimiento en la Constitución, la doctrina y la jurisprudencia lo han derivado de la disposición contenida en el artículo $19 \mathrm{~N}^{\circ} 3$ de la carta fundamental y lo han descrito como el único derecho global que considera un conjunto de garantías procesales, entre las que se cuenta el derecho a la defensa y a la prueba, entre otros. ${ }^{6}$

El derecho al debido proceso y los derechos implícitos que en él están contenidos, han sido jurisprudencialmente considerados como garantía de seguridad jurídica al individuo frente al poder. Esta seguridad, compartida con todo derecho incorporado al catálogo de Derechos Fundamentales, se manifiesta en límites o garantías irreductibles y esenciales en el Estado de Derecho. $^{7}$

Sin perjuicio del carácter valorativo o axiológico de los conceptos de un proceso racional y justo, el debido proceso incorpora el derecho a presentar e impugnar pruebas, cuya materialización en normas dependerá del sistema normativo específico del que se trate. En este sentido, la prueba como concepto esencial del derecho procesal, ${ }^{8}$ en sentido amplio, corresponde a "cualquier forma de fijación del hecho controvertido".

Como derivado del derecho a defensa, el derecho a la prueba para

1979 y 2009 declaró su violación en al menos 85 casos sobre garantías judiciales y otros 82 sobre el derecho a la protección judicial, muy por sobre otros derechos que han sido de conocimiento en casos ante la Corte. Cfr. GARCía, cit. (n. 3), p. 3.

${ }^{5}$ Artículos $24^{\circ}$ y $25^{\circ}$ de la Convención Americana de Derechos Humanos

${ }^{6}$ Es lo que López llama la función integradora del Debido Proceso. LóPEZ, Julián, "Debido proceso en Chile. Hacia un principio generador de reglas", en Bordalí, Andrés, Justicia Constitucional y derechos fundamentales, Lexis Nexis, Santiago, 2006, p. 186.

${ }^{7}$ Los derechos contenidos en el debido proceso han sido reunidos en la noción de procedimiento legal, justo y racional tanto por el Tribunal Constitucional (Por todos, V. Tribunal Constitucional, 7 de julio de 2011, Rol No 1838-2011, y Tribunal Constitucional, 7 de septiembre de 2010, Rol 1411-2010), como por la Corte Suprema (Por todos, V. Corte Suprema, 7 de octubre de 2004, Rol No 3304-04, y Corte Suprema, 14 de septiembre de 2005, Rol No 3666-05).

${ }^{8}$ Cfr. Couture, Eduardo, Fundamentos del Derecho Procesal Civil, B. de F., Montevideo - Buenos Aires, 2005, 4a ed. (reimpresión), p.178.

${ }^{9}$ Carnelutti, Francesco, La prueba civil, Depalma, Buenos Aires, 2000, $2^{\mathrm{a}}$ ed., p. 43. 
FERRER ${ }^{10}$ solo alcanza su plenitud bajo los presupuestos de una concepción racional, que rechace la vinculación de la prueba con el convencimiento íntimo psicológico del juez y se compone de los siguientes elementos: a) el derecho a utilizar todas las pruebas disponibles para demostrar la verdad de los hechos en que se funda la pretensión; b) el derecho a que las pruebas sean practicadas en el proceso maximizando la efectividad del principio de contradicción; c) el derecho a que las pruebas sean valoradas racionalmente, esto es, que sean consideradas en la decisión sobre los hechos y esa consideración sea racional y d) el derecho a que las decisiones judiciales sean motivadas.

\subsection{El debido proceso en la tipología de las normas}

El enunciado normativo contenido en el artículo $19 \mathrm{~N}^{\circ} 3$ inciso $6^{\circ}$ de la Constitución señala en su texto: "Toda sentencia de un órgano que ejerza jurisdicción debe fundarse en un proceso previo legalmente tramitado. Corresponderá al legislador establecer siempre las garantías de un procedimiento y una investigación racionales y justos". De este modo, este enunciado mandata la necesidad de que las sentencias jurisdiccionales se funden en procedimientos legales en que se garantice sean racionales y justos.

La noción de proceso racional y justo que utilizaré, a efecto de identificación de la norma en conflicto, es la utilizada por el Tribunal Constitucional que, en lo pertinente, señala que el procedimiento legal es racional si carece de arbitrariedad y es justo si cautela los derechos fundamentales de los participantes en un proceso. Uno de esos derechos fundamentales es el derecho a una adecuada defensa, la producción libre de pruebas conforme a la ley, el examen y objeción de la evidencia rendida. Por tanto, el debido proceso en su carácter justo, dado que cautela los derechos fundamentales de los partícipes, es aquel que cautela el derecho a la prueba.

Así, la norma del debido proceso, relativa al derecho a la prueba, consideramos puede ser reformulada del siguiente modo: El procedimiento legal, justo y racional, debe cautelar el derecho a la producción, examen y contraexamen de las pruebas. Reformulado en esos términos se trataría, en mi concepto, de un tipo de principio que ha sido descrito como una directriz

\footnotetext{
${ }^{10}$ Ferrer, Jordi. La valoración racional de la prueba, Marcial Pons, Madrid, 2007, p. 54 y ss.
} 
o norma programática, ${ }^{11}$ esto es, una norma que estipula la obligación de perseguir ciertos fines, los que pueden ser cumplidos de forma gradual, al modo de la noción de principio como mandato de optimización según Robert AleXy, cuándo distingue estos de las reglas que se cumplen o no. En las directrices, las condiciones de aplicación o el modelo de conducta esperado no están estipuladas. Atienza y Ruiz Manero distinguen las directrices de los principios en sentido estricto, que expresan valores superiores del ordenamiento como sería el de la igualdad, la justicia, entre otros.

Entendido el debido proceso como una directriz o norma programática o, como un principio o mandato de optimización, es posible sostener que pueden presentarse casos en los que su logro no es pleno y cede ante otros fines en colisión en el caso concreto. Este es el caso que, creo, se presenta cuando el debido proceso, en su versión derecho a la prueba, colisiona con otro derecho como es el del respeto al interés superior del niño.

Por tanto, sostengo que el derecho a la prueba, como integrante del derecho al debido proceso, es una directriz fundamentalmente por dos motivos. El primero de ellos es porque se trata de un principio que no cuenta con un modalizador deóntico como conector del caso genérico y su solución jurídica. Esta afirmación obliga precisar que, cuando utilizamos la palabra debe en nuestra reformulación, esta no es equivalente a obligatorio. No lo es porque el destinatario de nuestra reformulación es el juez ${ }^{12}$ que resuelve un caso concreto. Si fuere equivalente a obligatorio, las normas de admisibilidad de la prueba por motivos epistémicos o extra-epistémicos, y que justifican su exclusión (por ejemplo, la prueba ilícita) serían inaceptables, cuestión que no es posible entender en la formula binaria de cumplimiento o incumplimiento, propio de una norma obligatoria.

En el derecho a la prueba descrito por FERRER, ${ }^{13}$ el que el autor considere el derecho a utilizar todas las pruebas disponibles para demostrar la verdad de las afirmaciones sobre los hechos, no es equivalente a utilizar todas las pruebas. Son disponibles solo aquellas que, incorporadas al proceso, no han sido excluidas por algún motivo previsto en la ley.

\footnotetext{
${ }^{11}$ Atienza, Manuel; Ruzz Manero, Juan, Las piezas del Derecho, Editorial Ariel, Barcelona, 1996, p. 9

${ }^{12}$ Cuestión distinta es si el destinatario de la norma es el legislador, respecto del cual el constituyente mandata el aseguramiento de la justicia y racionalidad del procedimiento mediante la creación de la ley. Ahora, en este punto, me parece, se presentan otros problemas de caracterización de la norma, en tanto pudiere tratarse de una norma de competencia, más que una de mandato obligatoria deónticamente.

${ }^{13}$ FerRer, cit. (n. 10), p.52.
} 
El segundo motivo para sostener que el derecho a la prueba, como parte del debido proceso, es una directriz, por cuanto ordena perseguir ciertos fines, cumplidos de forma gradual. Así, utilizando nuevamente el esquema descriptivo de FERRER, ${ }^{14}$ el derecho a la prueba incorpora el derecho a presentar la prueba maximizando la contradicción. Pero, esto no es equivalente a una obligación. Maximizar la contradicción implica favorecer el debate entre las partes, como fórmula de adquisición de la prueba en el proceso. Sin embargo, la contradicción cede cuando hay otros fines, como es, en los hechos la protección de cierto tipo de testigos como son los niños, niñas y adolescentes, respecto de los cuales se adoptan fórmulas de comparecencia que limitan el contraste por parte de los intervinientes.

\section{El respeto al interés superior del niño en general}

\subsection{Generalidades}

La segunda norma que constituye el conflicto que presentaremos es la relativa al interés superior del niño. A continuación, revisaremos algunas generalidades y caracterización tipológica en relación a él.

En el Sistema Interamericano de Derechos Humanos la protección a los NNA emana primaria y generalmente de los artículos $1^{\circ}, 2^{\circ}$ y $19^{\circ}$ de la Convención Americana (en adelante $\mathrm{CADH}$ ), que establecen la obligación de respetar los derechos y libertades reconocidos por la convención y garantizar el libre y pleno ejercicio a toda persona sujeta a jurisdicción, sin discriminación alguna. ${ }^{15}$ Además, se establece que todo NNA tiene derecho a las medidas de protección que su condición de niño requiere por parte de su familia, de la sociedad y del Estado. ${ }^{16}$

La noción de niño emana de la Convención de Derechos del Niño ${ }^{17}$ (en adelante $\mathrm{CDN}$ ) y, en complemento con la $\mathrm{CADH}$, obliga a los Estados, en el contexto de un debido proceso, a garantizar la adopción de medidas de protección en su favor, a fin de que su intervención en procesos judiciales no

\footnotetext{
${ }^{14}$ Ferrer, cit. (n. 10), p.52.

${ }^{15}$ Artículos $1^{\circ}$ y $2^{\circ}$ Convención Americana de Derechos Humanos.

${ }^{16}$ Artículo $19^{\circ}$ Convención Americana de Derechos Humanos.

${ }^{17}$ Artículo $1^{\circ}$ Convención de Derechos del Niño (disponible en https://www.leychile.cl/ Navegar?idNorma=15824).
} 
implique una vulneración de sus derechos. ${ }^{18}$ En ese contexto, el artículo $3^{\circ}$ de la CDN identifica el interés superior del niño como el derecho que atraviesa todas las actuaciones de los organismos y agentes del Estado, cuando se trata de este grupo especialmente vulnerable en el contexto de la administración de justicia ${ }^{19}$ y que obliga a la autoridad a protegerlos y cuidarlos, procurando su bienestar y vigencia plena de sus derechos y garantías.

\subsection{El interés superior del niño en la tipología de las normas}

A partir de la noción de interés superior del niño que hemos indicado precedentemente, es posible reformular esta norma del siguiente modo: En todas las actuaciones de organismos y agentes del Estado, en el contexto de la administración de justicia, cuando se trate de NNA, se procurará su protección, cuidado y vigencia plena de sus derechos y garantías.

Así como el caso del debido proceso analizado presentemente, el enunciado reformulado en esos términos, creo, no cuenta con la estructura de norma de conducta que vincule un caso genérico a una solución normativa, utilizando un modalizador deóntico. ${ }^{20}$ Se trataría, una vez más, de un principio descrito como directriz o norma programática, ${ }^{21}$ que estipula la obligación de perseguir ciertos fines, los que pueden ser cumplidos de forma gradual, al modo de la noción de principio como mandato de optimización de Robert AleXy, cuando este los distingue de las reglas. Para el caso, el ejemplo que Atienza y Ruiz Manero utilizan para describir una directriz, ${ }^{22}$ coincide de forma significativa con la norma que hemos reformulado relativa al interés

\footnotetext{
${ }^{18}$ Artículos $8^{\circ}$ y $25^{\circ}$ Convención Americana de Derechos Humanos.

${ }^{19}$ En la Opinión Consultiva $\mathrm{N}^{\circ} 17$ del año 2002 la Corte se pronunció sobre la condición jurídica y derechos humanos de los NNA, al tenor de las normas contenidas en la CADH, y señaló que, Párrafo 96: "Es evidente que las condiciones en las que participa un niño en un proceso no son las mismas en que lo hace un adulto. Si se sostuviera otra cosa se desconocería la realidad y se omitiría la adopción de medidas especiales para la protección de los niños, con grave perjuicio para estos mismos. Por lo tanto, es indispensable reconocer y respetar las diferencias de trato que corresponden a diferencias de situación, entre quienes participan en un procedimiento". Corte Interamericana de Derechos Humanos, Opinión Consultiva N ${ }^{\circ} 17$ de 2002 (disponible en http://www.corteidh.or.cr/docs/opiniones/seriea_17_esp.pdf [consulta 13 de abril 2020]). Desde el punto de vista jurisprudencial e interpretativo, la Corte IDH ha referido al mandato de protección de los NNA en el caso Villagrán Morales y Otros vs. Guatemala (caso de los niños de la calle), en el que se releva la necesidad de atender especialmente la condición de niños para comprender el alcance de la obligación de protección del Estado.

${ }^{20}$ Agüero-SAn Juan, Sebastián, "Las antinomias y sus condiciones de surgimiento. Una propuesta para los enunciados normativos", Revista de Derecho de Valdivia, 2015, Vol. 28, n 2, p.33.

${ }^{21}$ Atienza; Ruiz Manero, cit. (n. 11), p. 9

${ }^{22}$ Atienza; Ruiz Manero, cit. (n. 11), p. 3.
} 
superior del niño. Utilizando el mismo recurso, me parece que no se trata en el caso de un principio en sentido estricto como sería el caso de la igualdad ante la ley, ejemplo utilizado por los mismos autores para graficar aquellos principios que representan valores superiores del ordenamiento jurídico.

3. Rendimiento de la Teoría de la Ponderación como forma de análisis del conflicto entre el principio del debido proceso y el principio del interés superior del niño

\subsection{El conflicto en contexto. Los supuestos de hecho que conoce el agente} (el juez)

Los ejemplos en el proceso penal en los que se tensiona el debido proceso como derecho a la prueba y el interés superior del NNA son variados. En general, las tensiones se producen a propósito de la participación de este tipo de víctimas en el juicio oral y, en particular, con motivo de la incorporación de su testimonio de forma directa como prueba.

La Ley de EIV establece que los NNA víctimas que deban comparecer al juicio oral, deben declarar en una sala especial, distinta de aquella donde se realiza la audiencia y solo en presencia de un entrevistador, quien cumple la función de intermediador entre los intervinientes y el niño. ${ }^{23}$ Respecto de la figura del intermediador volveremos más adelante. Por ahora, me concentraré en una situación concreta, aunque hipotética, en la que un juez deberá decidir acerca de la primacía de un principio sobre otro. Se trata de supuestos de hecho en los que se vería sometido el juez a una decisión antinómica que utilizaré de modo ilustrativo para evaluar el rendimiento de la Teoría de la Ponderación como forma de análisis y para la obtención de una solución al caso propuesto. Como ejemplo, aunque limitado, pretendo que dé cuenta de una forma de análisis y solución útil para otros conflictos de estas características que pudieren presentarse durante el juicio oral.

Vigente la Ley EIV, la participación de un NNA en un juicio oral queda regulada por sus normas, indistintamente si se trata de un caso cuya investigación o judicialización se inició con anterioridad a dicha vigencia. Por tanto, al menos durante el primer tiempo, habrá juicios orales en los que se recibirá la declaración judicial de una víctima, cuyo testimonio recibido en la etapa de investigación ante el Ministerio Público, no fue videograbado

${ }^{23}$ Art. 13 y siguientes de la Ley de EIV. 
de acuerdo a las formas de esta ley, por no haberse encontrado vigente a esa época. Se tratará, de acuerdo a la práctica habitual anterior a esta normativa, de una declaración investigativa mecanografiada por un fiscal o un policía no especializado.

Según la Ley de EIV, para demostrar contradicciones o inconsistencias entre lo declarado por el NNA en el juicio y las declaraciones que previamente hubiere prestado durante la etapa de investigación, excepcionalmente, los intervinientes pueden solicitar al juez la incorporación y reproducción del registro de video de la entrevista investigativa. La confrontación no podrá materializarse en presencia del NNA y se practicará entre el registro de la entrevista investigativa y la declaración judicial, una vez que esta última ya hubiere terminado. ${ }^{24}$

Sin embargo, la ley no considera el supuesto en que la declaración de la etapa investigativa utilizada para confrontar no conste en video. En este caso, para configurar el conflicto normativo hipotético que analizaré, supondré que el defensor en su contrainterrogatorio ha solicitado al juez la incorporación de una declaración de la etapa de investigación transcrita y firmada por el niño ante el fiscal, tal como lo regula la ley procesal penal para la generalidad de testigos en juicio. ${ }^{25}$ En el caso, el defensor no tiene

${ }^{24}$ La situación está regulada en los artículos 17 y 18 letra c) de la Ley de EIV.

${ }^{25}$ Se trata de la facultad normada en la disposición del artículo 332, en relación al 330 inciso segundo, ambas del Código Procesal Penal. La confrontación en el contra examen de un testigo de cargo, ya sea para desacreditarlo a él o a su testimonio, se configura como parte del núcleo esencial del derecho a la defensa y, por tanto, al debido proceso. Cfr. DuCE, Mauricio, "Derecho a la confrontación y uso de declaraciones emitidas en un juicio previo anulado", Revista Política Criminal, 2014. Vol. 9, n 17 , p.131

Un caso interesante, aunque distinto al hipotético planteado en el trabajo, es el que se produjo en el juicio oral seguido ante el Tribunal de Juicio Oral en lo Penal de Antofagasta, por delito de violación, en RUC 2000519605-2. En el caso, el Tribunal Oral en su sentencia, consideró complementarias la declaración judicial y la entrevista investigativa incorporada excepcionalmente al juicio oral en virtud de la norma del artículo 18 letra c) de la Ley de EIV, lo que utilizó el sentenciador para valorar significativamente el testimonio de la víctima y condenar por el delito imputado. En el caso, el Ministerio Público solicitó la incorporación del registro de entrevista video grabada practicada en la etapa de investigación, a fin de mostrar contradicciones, imprecisiones y complementar el relato del NNA. Esta disposición de la Ley de EIV debe relacionarse con la situación normada por el artículo 332 del Código Procesal Penal. Si bien la situación fue discutida en el contexto de un recurso de nulidad, la Corte de Apelaciones de Antofagasta en sentencia Rol $N^{\circ} 166$ del 2021, rechazó las alegaciones y reafirmó lo dicho por el Tribunal Oral respecto de la complementariedad de ambos testimonios (Considerando $6^{\circ}$ ). Esta situación, producida por la norma del artículo 18 de la Ley de EIV produce conflictos normativos que ya habían sido descritos y anticipados en el proceso de tramitación de la ley en el Congreso Nacional por los representantes de la Defensoría Penal Pública, dado que, según expusieron se trata de diligencias y registros de diligencias dirigidas exclusivamente por el Ministerio Público, sin consideración de 
disponible una entrevista investigativa y argumenta que, dado que no se trata del supuesto previsto por la Ley de EIV, entonces debe aplicarse la regla general de confrontación, esto es, con el NNA aún presente en la audiencia, exhibiendo el registro. Luego, agrega el defensor que así, y solo así, se garantizaría el debido proceso y el derecho a la prueba del acusado.

De otro lado, el fiscal se ha opuesto a la solicitud de la defensa, pidiendo al juez su desestimación en razón del respeto al interés superior del niño y de la prevención de su victimización secundaria. ${ }^{26}$

Descrito así el caso, utilizando las normas reformuladas en apartados anteriores, el conflicto se produce entre la norma que establece al juez que "El procedimiento legal, justo y racional, debe cautelar el derecho a la producción, examen y contraexamen de las pruebas" y aquella que establece que "En todas las actuaciones de organismos y agentes del Estado, en el contexto de la administración de justicia, cuando se trate de NNA, se procurará su protección, cuidado y vigencia plena de sus derechos y garantías”. Entonces ¿Cómo debe resolver el juez el conflicto? Si se autoriza que la víctima sea confrontada por la defensa de acuerdo a las reglas generales de la ley procesal penal, entonces se resolverá la primacía del debido proceso. $\mathrm{Si}$, por el contrario, la solicitud fuere rechazada, entonces lo será declarando la primacía del respeto al interés superior del niño.

Evidentemente, el conflicto no se ha producido del solo tenor de las normas reformuladas. No hay, en abstracto, más allá de las circunstancias del caso, conflicto entre los principios enunciados. No se trata de un problema de coherencia abstracta del sistema, o un problema en que los supuestos de hecho de las normas colisionen del punto de vista discursivo, semántico del sistema de fuentes. Se trata de un conflicto que surge para el juez, a partir de una circunstancia concreta. La distinción entre antinomias en abstracto y en concreto ${ }^{27}$ la retomaremos en los apartados siguientes. Para efectos de nuestro análisis y presentación del conflicto entre los principios del debido proceso como derecho a la prueba y el de respeto al interés superior del niño, basta con decir, por ahora, que se trata de una antinomia en concreto cuyo

\footnotetext{
principios como el de bilateralidad de la audiencia o inmediación, los que forman parte del debido proceso en su expresión derecho a la prueba. Cfr. Biblioteca del Congreso Nacional (Eds.), Historia de la Ley 21.057, disponible en https://www.ben.cl/historiadelaley/nc/historia-de-la-ley/7481/ [última visita 30 de abril de 2021], pp. 271 y ss.

${ }^{26}$ Se trata del objeto declarado de la Ley de EIV, en la disposición del artículo $1^{\circ}$.

${ }^{27}$ Cfr. Guastini, cit. (n. 2), p.538.
} 
supuesto de hecho surge de una defensa que solicita al juez penal confrontar al NNA de acuerdo a las reglas generales del juicio oral, es decir, se produce en el concreto contexto fáctico del agente.

Para la decisión (o solución), el juez ponderará ambos principios para preferir uno de ellos. GUASTINI nos recuerda que los principios constitucionales tienden a entrar en conflicto, fundamentalmente, por la pluralidad de valores ético políticos que en ellos se ven implicados. Dado que no es posible excepcionar o derogar uno de los principios en conflicto, como se haría con una antinomia entre reglas, el juez deberá establecer lo que GuASTINI ha denominado una "jerarquía axiológica móvil", esto es, una jerarquía entre el valor, el peso o la importancia de uno por sobre el otro. ${ }^{28}$ Este razonamiento para la decisión sobre si se accede o no a la confrontación de acuerdo a las normas generales del proceso penal, es un razonamiento de ponderación. Cómo establecer la jerarquía axiológica para la resolución del caso concreto y los problemas de control de ese razonamiento, son cuestiones que han presentado problemas teóricos de cuyo alcance referiremos a continuación. ${ }^{29}$

\subsection{El conflicto y la Teoría de la Ponderación}

La Teoría de la Ponderación ha sido desarrollada por la Teoría del Derecho a partir de la propuesta formulada por Robert AleXY en su obra "Teoría de los Derechos Fundamentales". ${ }^{30}$ Para su descripción es necesario distinguir, dos tipos de normas, los principios por una parte y las reglas por otra. En ambos tipos de normas es posible encontrar estructuralmente modalizadores deónticos del tipo, mandatos, permisiones y prohibiciones, a partir de los cuales se expresan razones a los destinatarios de la norma, respecto de lo que se debe hacer.

Distinguiendo, los principios son normas que ordenan la realización de algo en la mayor medida posible, teniendo presente las posibilidades fácticas y jurídicas aplicables al caso. De otro lado, las reglas son normas que pueden ser cumplidas o no, de forma determinada. En este sentido, sostiene Alexy, la diferencia entre principios y reglas no radica en la generalidad

\footnotetext{
${ }^{28}$ Cfr., Guastini, Riccardo. Interpretar y Argumentar, Centro de Estudios Políticos y Constitucionales, Madrid, 2014, p.213.

${ }^{29}$ Cfr., Moreso, José Juan, La Constitución, Un Modelo Para Armar, Marcial Pons, Madrid, 2009, p.271.

${ }^{30}$ Alexy, Robert, Teoría de los Derechos Fundamentales, Centro de Estudios Constitucionales, Madrid, 2002, p.83 y ss.
} 
de los primeros y especificidad de las segundas, no siendo una cuestión de grado, sino cualitativa. ${ }^{31}$

Los conflictos normativos, de acuerdo a lo que ya tratamos, corresponden a los producidos entre normas, principios o reglas, que, aplicadas de forma independiente a un caso, producen resultados incompatibles o contradictorios. Estos conflictos se producen de forma diversa en el caso de principios y reglas. En el caso del conflicto normativo producido entre reglas, estas deben solucionarse mediante la introducción de una excepción o la declaración de invalidez de una de ellas. En efecto, en el conflicto entre reglas, al modo de la "contradicción normativa" de HAMNER HiLl, ${ }^{32}$ la conducta obligatoria a la que se somete el agente en virtud de una norma, es prohibida en el mismo caso, para el mismo agente, en virtud de una norma diversa. La solución solo puede hallarse mediante la introducción de la excepción o eliminación de una de las reglas.

En el caso de los principios, los conflictos operan de forma distinta. ${ }^{33}$ De acuerdo a AlEXY, cuando dos principios están en conflicto, dado que se trata de "mandatos de optimización", esto es, normas que no se cumplen o dejan de cumplir, sino que se cumplen en la mayor medida de lo posible, de acuerdo a las condiciones jurídicas y fácticas, entonces, uno de esos principios en colisión debe ceder al otro. Esa cesión de un principio se fundamenta en la consideración a esas circunstancias concretas que explican que el principio predominante lo sea, en razón de su peso o valor que ha sido ponderado. Lo que ha ocurrido en el caso, describe Alexy, es una "preferencia condicionada" por el carácter contextual en que se produce. Son las condiciones del caso las que determinan la preminencia de uno sobre el otro. ${ }^{34}$

Volviendo sobre el ejemplo que hemos utilizado, las circunstancias concretas del caso a partir de las cuales el agente debe condicionar la preminencia de un principio estarían dadas por la revictimización que se

\footnotetext{
${ }^{31}$ Cfr. Alexy, cit. (n. 28), p.87.

${ }^{32}$ HamNer Hill, H. "A functional taxonomy of normative conflict", Law and Philosophy Review, 1987, Vol. 6, pp. 227-247, https://doi.org/10.1007/BF00145430 (consultada: 13 de abril 2020), p. 239.

${ }^{33}$ Cfr. Alexy, cit. (n. 30), p. 89.

${ }^{34}$ Para Moreso, la preferencia condicionada por circunstancias concretas del caso corresponde a la especificación de las condiciones de aplicación del principio por parte del agente en condiciones delimitadas. Sería esta propuesta especificacionista, la descripción de una etapa en el proceso subsuntivo para la obtención de una regla aplicable al problema normativo. Cfr. Moreso, cit. (n. 29), p.315 y ss.
} 
pretende evitar en el NNA a quien se pretende confrontar. En ese punto, el juez como agente enfrentando a la antinomia, valora, pesa o da un cierto nivel de importancia superior, por ejemplo, a la edad de la víctima, su disponibilidad respecto de su comparecencia y actuación procesal, ciertos detalles del hecho motivo de la imputación penal y el testimonio y la victimización general que afecta al niño, por sobre afectar el debido proceso, e incluso, por sobre la posibilidad de afectar la calidad de la información incorporada al juicio por la prueba testimonial.

Para ponderar, AlEXY desarrolla una fórmula de razonamiento en tres pasos, de tal modo de, en el primero, establecer el grado de no satisfacción de un principio. En el segundo, establecer el grado de satisfacción del principio que pugna con el primero y, en el tercero, evaluar la importancia de la satisfacción del segundo principio ponderado. Así, en el ejemplo, debiera el juez ser capaz de establecer cuánto se sacrifica el debido proceso con la denegación de la confrontación solicitada; cuánto se satisface el interés superior del niño con tal decisión y cuán importante es satisfacer el interés superior del niño. Esa satisfacción y sacrificio pudiere ser leve, media o grave. Para el caso, Alexy propone un análisis numérico o aritmético que ha sido motivo de cuestionamiento. ${ }^{35} \mathrm{Al}$ respecto, resulta difícil racionalmente establecer inequívocamente que se considerará leve, media o grave, sin que exista un estándar para asignar el valor, peso o importancia a la satisfacción o sacrificio del principio.

La Teoría de la Ponderación, también ha sido desarrollada por Riccardo GuAstini, quien ha descrito cuatro características para conflictos entre principios constitucionales. ${ }^{36}$ En virtud de ellas, estos se identifican por: 1) producirse, normalmente, entre normas promulgadas en el mismo momento; 2) se trata de normas que tienen el mismo estatuto y jerarquía; 3 ) se trata de un conflicto en concreto, producido con ocasión de la aplicación de los principios a la resolución de un caso; 4) se trata de un conflicto parcial bilateral, esto es, se produce respecto de los supuestos de hecho que sirven de antecedente de ambos principios, que por su apertura, no implican una superposición total.

En el caso de nuestro ejemplo, no es posible distinguir si el debido

\footnotetext{
${ }^{35}$ Cfr. Moreso, cit. (n. 29), p. 311.

${ }^{36}$ Guastini, cit. (n. 28), p. 213. También en Guastins, Riccardo. La Sintaxis del Derecho, Editorial Marcial Pons. Madrid. 2016, p. 261 y ss.
} 
proceso y el interés superior del niño fueron normas promulgadas en el mismo momento (pues no emanan del mismo cuerpo normativo), pero si es posible sostener que tienen la misma jerarquía y estatuto. ${ }^{37}$ De igual modo, ya he indicado cómo el conflicto se produce en concreto y en la tipología de las normas ha quedado en evidencia que la superposición de los supuestos de hecho de ambos principios no es total.

Utilizaré algunos elementos adicionales de la teoría de la ponderación de Guastini para ilustrar los dos conflictos restantes que analizaremos, esta vez, a partir de enunciados normativos específicos de la ley 21.057. Lo desarrollaré de este modo, pues la descripción que hace GuASTINI de la concreción de principios en reglas favorece su aplicación práctica, guiando al operador en el proceso hacia la obtención de una solución al conflicto normativo al que está sometido.

\section{LA CONCRECIÓN DE PRINCIPIOS DE GUASTINI}

\section{Generalidades sobre la concreción}

Siguiendo a Riccardo GuAstini, ${ }^{38}$ cuando se trata de principios constitucionales es necesario hacer algunas consideraciones previas para analizar el conflicto normativo. En primer lugar, respecto del ejercicio de aplicación de un principio, ya sea por parte de un juez constitucional que confronta una norma legal con un principio constitucional de rango superior, o por un juez común que busca resolver una laguna legal para la resolución de un caso, siempre es necesario previamente concretar el principio constitucional. La concreción implica utilizar el principio como premisa de un razonamiento jurídico en que el resultado es la formulación o creación de una regla no formulada que, especificada, permite la resolución del caso. ${ }^{39}$

\footnotetext{
${ }^{37}$ Especialmente de acuerdo artículo $5^{\circ}$ de la Constitución y el reenvío que hace a los Tratados Internacionales de DDHH.

${ }^{38}$ Cfr. Guastini, cit. (n. 28), p. 211.

${ }^{39}$ Cfr. Guastini, cit. (n. 28), p. 212. En un sentido similar al descrito por Guastini, José Juan Moreso concreta principios en reglas mediante la especificación de las condiciones de aplicación de los primeros que, en términos estructurales, siempre son abiertos en su antecedente. Para Moreso, la delimitación de dichas condiciones relevantes del caso produce una regla aplicable a la generalidad
} 
De esta forma, una alternativa analítica, adicional al posible conflicto directo entre principios del debido proceso y el interés superior del niño, es el conflicto entre las reglas establecidas en la ley de EIV y reglas especificadas a partir del principio del debido proceso en su versión de derecho a la prueba. Así, utilizaré la siguiente reformulación del principio del debido proceso: El procedimiento legal, justo y racional, debe cautelar el derecho a la producción, examen y contraexamen de las pruebas. A partir de esta noción de debido proceso, es posible entender que se especifican las siguientes reglas, a modo de extracción de normas implícitas contenidas en el enunciado original. Primero: En un proceso legal, es obligatorio cautelar la producción de prueba. Segundo, una regla del siguiente tenor: En un proceso legal, es obligatorio cautelar el examen y contra examen de la prueba.

A continuación, identificaré dos reglas extraídas de enunciados de la Ley de EIV, las que presentaré en conflicto con las reglas que hemos concretizado del principio del debido proceso. Una vez identificadas y categorizadas en la tipología de las normas, analizaré los dos conflictos desde la taxonomía de conflictos ofrecida por la Teoría del Derecho, a la que ya he referido previamente y que detallaré en las secciones siguientes.

\section{El interés superior del niño en las normas de la ley de EIV}

El interés superior ha sido plasmado en el artículo $3^{\circ}$ de la Ley de EIV, generando múltiples consecuencias para la práctica jurídica y facilitando de paso la generación de contextos para la producción de conflictos normativos.

de aquellos otros casos que también las contengan. En este sentido, propone la concreción hecha por el agente como una etapa en el razonamiento de subsunción, y responde a una de las dudas que a su juicio presenta la teoría de la ponderación de ALEXY, que califica de excesivamente particularista y justificadora de reglas ad hoc. MORESO describe este razonamiento subsuntivo en cinco etapas: 1) la delimitación del problema normativo dentro del ámbito de las acciones humanas (como serían en nuestro caso las características del NNA y la etapa del proceso en que se encuentre relativa a la entrega de copias o interrogatorios al NNA); 2) la identificación de las pautas-prima facie- aplicables a ese ámbito de acciones; 3) la consideración de casos paradigmáticos de ese ámbito normativo, al modo de delimitación de las reconstrucciones posibles; 4) el establecimiento de las propiedades relevantes en el universo del discurso para una posible solución normativa al problema (como sería la victimización o vulnerabilidad del NNA, entre otras); 5) la formulación de una regla que resuelve de modo univoco todos los casos contenidos en el universo del discurso seleccionado previamente. Se trata, en definitiva, de una propuesta especificacionista, de carácter general, capaz de resolver todos los casos previamente delimitados, a diferencia de la particularista propuesta de Alexy. Cfr. Moreso, cit. (n. 29), p. 317. 
En efecto, desde un punto de vista práctico, la investigación de los delitos ${ }^{40}$ en los que la víctima es un NNA es especialmente compleja, tanto por los hechos y la prueba de ellos, como por la condición de niño que ostenta la víctima. Este ejercicio de identificación implica poner de relieve que, el debido proceso alcanza no solo la etapa de juicio oral, sino también todas las actuaciones de la investigación que realiza el Ministerio Público y las de la etapa intermedia. Es así que, desde el punto de vista del imputado, cobran especial importancia determinados estándares de defensa propios de un sistema de enjuiciamiento penal contradictorio como es el chileno, que en su faceta de equilibrio e igualdad de armas entre los intervinientes, exige, entre otros, el debido acceso a la imputación, los antecedentes, copias y registros de la indagatoria estatal y acceso a contraexaminar la prueba de cargo, todas cuestiones que han sido de especial relevancia para la Corte IDH. ${ }^{41}$

\section{A. Identificación de la norma que regula la reserva de la entrevista y limita el acceso de copias. Tipología}

En la Ley de EIV, la disponibilidad de copias y registros de la entrevista en la que consta el testimonio de la víctima está restringida de forma especial mediante la incorporación de controles adicionales a los previstos en la regla general que otorga conocimiento a los intervinientes. ${ }^{42}$ En particular, en aplicación del principio de interés superior del niño, el sistema normativo establece la siguiente regla en su artículo $23^{\circ}$ inciso $2^{\circ}$ : "Los intervinientes, las policías y los peritos podrán obtener copia del registro de la entrevista investigativa videograbada,

\footnotetext{
${ }^{40} \mathrm{El}$ artículo $1^{\circ}$ del proyecto de ley de EIV establece que es aplicable a los siguientes delitos del Código Penal: violación; estupro y otros delitos sexuales, arts. 361 y ss; Secuestro, artículos 141, incisos cuarto y quinto; 142; violación con homicidio artículo 372 bis; Comercio, importe, exporta, distribuya, difunda o exhiba Material Pornográfico infantil Art. 374 bis; Parricidio y femicidio. Art. 390; Homicidio. Art. 391; Lesiones Castración. Art. 395; Lesiones Graves Gravísimas. Art. 397, № 1; Tráfico de Migrantes. Art. 411 bis; Trata de Personas. Art. 411 ter y 411 quáter; Robo con homicidio, violación o lesiones que indica. Art. 433, $\mathrm{N}^{\circ} 1$.

${ }^{41}$ Ver. Caso Radilla Pacheco vs. México (2009), Párrafo No 256. "La Corte considera que, en casos como el presente, la negativa de expedir copias del expediente de la investigación a las víctimas constituye una carga desproporcionada en su perjuicio, incompatible con el derecho a su participación en la averiguación previa. En el caso que nos ocupa, esto se tradujo en una violación del derecho de la señora Tita Radilla Martínez a participar plenamente en la investigación. Al respecto, los Estados deben contar con mecanismos menos lesivos al derecho de acceso a la justicia para proteger la difusión del contenido de las investigaciones en curso y la integridad de los expedientes."

${ }^{42}$ Artículo 182 del Código Procesal Penal.
} 
debiendo el fiscal entregarla, siempre que se hubiere distorsionado suficientemente aquellos elementos de la videograbación que permitan identificar al niño, niña o adolescente, sin que ello afecte su comprensión. Asimismo, las personas precedentemente indicadas podrán acceder al contenido íntegro y fidedigno de la entrevista investigativa videograbada, sin las distorsiones mencionadas, sólo mediante su exhibición en dependencias del Ministerio Público, debiendo siempre velar por el respeto de los derechos de los demás intervinientes".

Para evidenciar los conflictos normativos que presentamos, utilizaré la primera parte del texto citado. Así, descomponiéndolo estructuralmente, un primer enunciado es del siguiente tenor: "Los intervinientes, las policías y los peritos podrán obtener copia del registro de la entrevista investigativa videograbada". Luego, sin embargo, el enunciado indica “...debiendo el fiscal entregarla, siempre que se hubiere distorsionado suficientemente aquellos elementos de la videograbación que permitan identificar al niño, niña o adolescente, sin que ello afecte su comprensión". Así, la norma que se desprende del enunciado lo reformulamos del siguiente modo: El Fiscal está obligado a entregar las copias de la declaración del NNA distorsionadas al interviniente que lo haya solicitado. Se trata de una norma de conducta que vincula al Fiscal (caso genérico) con la entrega de las copias solicitada (solución normativa), mediante un modalizador deóntico equivalente a una obligación. ${ }^{43}$

Identificada la norma, se trataría de una de tipo prescriptivo que ordena ejecutar determinada conducta, si se dan ciertos supuestos, pretendiendo influir en el comportamiento del agente. ${ }^{44}$ De otro lado, puede ser entendida igualmente, como una norma regulativa que establece una obligación. ${ }^{45}$

\footnotetext{
${ }^{43}$ Agüero-San Juan, cit. (n. 20), p. 33.

${ }^{44}$ Moreso, José Juan; Vilajosana, Josep María, Introducción a la teoría del derecho, Editorial Marcial Pons, 2014, p. 63.

${ }^{45}$ Atienza; Ruiz Manero, cit. (n. 11), p. 65
} 
2.B. Identificación de la norma que regula el interrogatorio y contrainterrogatorio al niño. Tipología

Un segundo enunciado normativo que utilizaremos como parte del conflicto normativo con el debido proceso es el relativo al examen y contraexamen de los litigantes al testimonio que presta un NNA en juicio oral. El examen y contra examen está limitado en resguardo del principio del interés superior, obligando a los intervinientes a que, aquella pregunta formulada durante el juicio oral, sea dirigida a un intermediario designado, quien la reformulará en los términos que estime sea adecuada a las características del niño. La cuestión tiene impacto en la forma en la que la prueba testimonial se rinde en juicio, en la inmediación, control y acceso de los intervinientes, especialmente desde el derecho al debido proceso y prueba, como trataremos en su oportunidad. Así, el texto del enunciado normativo es del siguiente tenor:

"Los intervinientes dirigirán sus preguntas al juez, quien, en su caso, las transmitirá al entrevistador. Éste, a su vez, deberá plantear al niño, niña o adolescente las preguntas en un lenguaje y modo adecuados a su edad, madurez y condición psíquica" (artículo 17. Inciso $3^{\circ}$ ).

Por tanto, entenderé y reformularé la norma como la que sigue: Los intervinientes tienen prohibido dirigir preguntas directas al NNA. Vista así la norma, se trataría de una regulativa ${ }^{46}$, prescriptiva $^{47}$ y prohibitiva, ${ }^{48}$ con una formulación deóntica de modo prohibición emanada de la autoridad.

A continuación, analizaremos los dos conflictos que se producen entre las cuatro reglas que hemos identificado, reformulado o concretizado. Será este el último paso analítico previo a la presentación de algunas conclusiones a modo de consideraciones finales.

\footnotetext{
${ }^{46}$ Agüero-San Juan, cit. (n. 20), p. 33.

${ }^{47}$ Moreso y Vilajosana, cit. (n. 44), p. 63

${ }^{48}$ Moreso y Vilajosana, cit. (n. 44), p. 62
} 


\section{UBICACIÓN DE LOS CONFLICTOS NORMATIVOS IDENTIFICADOS EN LAS TAXONOMÍAS OFRECIDAS POR LA TEORÍA DEL DERECHO}

\section{Cuestiones previas}

A continuación, me abocaré a la descripción de los conflictos producidos entre las normas identificadas, con la pretensión de ubicarlos en las alternativas que se han ofrecido desde la Teoría del Derecho. Para este fin, utilizaré una primera sección explicativa de una tipología de conflictos, fundamentalmente a partir de los trabajos de Stephen Munzer y H. Hamner HiLl, publicados en 1973 y 1987, respectivamente.

Como cuestión preliminar, vuelvo sobre la noción de antinomia de GUASTINI ${ }^{49}$ en virtud de la cual esta se presenta cuando dos normas establecen para el mismo supuesto de hecho consecuencias incompatibles entre sí.

Así como para GuAstinI ${ }^{50}$ las antinomias se producen en abstracto o en concreto, para MunZER, ${ }^{51}$ la cuestión relevante radica en la distinción entre los conflictos normativos que producen una incompatibilidad inmediata entre dos normas, de aquellos cuya incompatibilidad está mediatizada por la realidad. En el primer caso, se trata de un conflicto entre dos normas contenedoras de modalizadores deónticos que prescriben conductas al agente que de su solo tenor resultan incompatibles. Estos conflictos se producen, por ejemplo, en el caso de que, dada una situación determinada, una norma obligue a hacer "a" y otra, en la misma situación o contexto, obligue a hacer "b", siendo "a" y "b" incompatibles de realizarse conjuntamente. En el mismo sentido, es un conflicto antinómico del modo descrito por Munzer, aquel que se produce en una situación determinada en que el agente tiene una norma que le permite hacer "a" y otra, en el mismo contexto, que le obliga a hacer "b", siendo "a" y "b", incompatibles en ese contexto en que se encuentra el agente.

\footnotetext{
${ }^{49}$ Guastini, cit. (n. 2), p. 537. En un sentido similar, Martínez Zorrilla identifica el conflicto como el producido en aquella situación en que un sujeto no puede adecuar su comportamiento a las exigencias de un conjunto de normas aplicables al caso en que se encuentra, provocando la elección de una de ellas y el incumplimiento de la otra. Cfr. Martínez, David, Conflictos Constitucionales. Ponderación e Indeterminación Normativa, Marcial Pons, Madrid, 2007, p. 87. En sentido similar, Ausín, Txetxum, Entre la lógica y el Derecho. Paradojas y conflictos constitucionales, Plaza y Valdés Editores, México D.F., 2005, p. 132.

${ }^{50}$ GuAstini, cit. (n. 3), p. 238.

${ }^{51}$ Munzer, Stephen, "Validity and legal conflicts", Yale Law Review, 1973, No 82, p. 1144.
} 
Los conflictos normativos antinómicos descritos se distinguen de aquellos en que la incompatibilidad se produce por un contexto de realidad concreto que hace que dos normas sean incompatibles para el agente en el caso. ${ }^{52}$ La descripción del conflicto dice relación con normas que regulan situaciones diversas y que en abstracto no colisionan, porque no hay necesaria coincidencia en sus supuestos de hecho. Sin embargo, en el caso concreto el agente se enfrenta a la posibilidad de aplicar ambas de forma simultánea.

Una manera distinta de entender los conflictos normativos es la propuesta de H. HAMNER HiLl, ${ }^{53}$ quien ofrece una caracterización de ellos que adiciona un énfasis en la función, fuerza, objetivo y propósito de las normas de las que se trata, es decir, entiende el conflicto como aquel que implica la interferencia de una norma en el funcionamiento, propósito o medios para alcanzar el propósito de otra en el mismo sistema. En particular, distingue entre contradicción, colisión y competición normativa.

La contradicción normativa ${ }^{54}$ corresponde al conflicto tradicional, esto es, aquel que se produce entre normas incompatibles o contradictorias deónticamente, explicado mediante la imposibilidad de obediencia conjunta. Esta se distingue de la colisión normativa producida por normas contenedoras de imperativos $\mathrm{u}$ obligaciones con normas permisivas, o, conflictos entre normas permisivas, de un mismo sistema jurídico. ${ }^{55}$ En estos casos, el agente tendría la posibilidad de evitar el conflicto de acuerdo al contenido de la norma permisiva, antes de que surja la colisión. Se trataría de una incompatibilidad funcional antes que lógica, dado que una norma impediría el funcionamiento de la otra. La diferencia fundamental de la colisión con la contradicción normativa radica en la presencia de normas permisivas. Las permisiones no pueden ser cumplidas o incumplidas. ${ }^{56}$ Podría, en este sentido, darse el caso de que el agente sometido al conflicto normativo no vulnere ninguna de las dos normas, si estas son permisos.

Por último, Hamner HILL ${ }^{57}$ identifica como competencia normativa

\footnotetext{
${ }^{52}$ Para Ausin se trata de conflictos denominados "Paranómicos". Cfr. Ausín, cit. (n. 49), p. 132.

${ }^{53}$ Hamner Hill, cit. (n. 32), p. 238.

${ }^{54}$ Hamner Hill, cit. (n. 32), p.239.

${ }^{55}$ Hamner Hill, cit. (n. 32), p.241.

${ }^{56}$ Hamner Hill, cit. (n. 32), p.230.

${ }^{57}$ Hamner Hill, cit. (n. 32), p.244.
} 
(Normative Competitions) aquel conflicto no deóntico que se produce entre dos normas que compiten por ser aplicadas a un caso concreto, eventualmente, desde dos sistemas normativos o jurisdicciones distintas. Se trata de dos normas legales que colisionan por determinado ámbito de competencia, debiendo resultar una excluida. Expresamente, HAMnER HiLl distingue este tipo de conflicto de la colisión normativa, dado que esta última se produce necesariamente en el mismo sistema normativo. En una competición normativa, una norma que es efectivamente ejecutada o cumplida por el agente, frustra la otra norma que previamente pudo ser aplicable al caso. En este último caso, la competición normativa puede implicar el conflicto entre los medios elegidos por el agente para la prosecución de los fines u objetivos de las normas antinómicas.

Por tanto, en síntesis, de los conflictos normativos descritos precedentemente es posible identificar al menos tres situaciones diferentes, consistentes con los trabajos de Hamner HiLl, Munzer y la recepción que se ellos han hecho otros contemporáneos como Ausin o Martínez Zorrilla. ${ }^{58}$ El primer caso corresponde al conflicto que se presenta en abstracto en normas de obediencia o cumplimiento, normas de mandato o prescriptivas. A su respecto, el conflicto normativo se produce cuando la obediencia a ambas normas resulta lógicamente inconsistente, al modo de la regla que obliga y otra prohíbe actuar al sujeto o, al contrario. El segundo caso es el que describe el conflicto que se presenta cuando el cumplimiento conjunto de dos normas es imposible vía determinados hechos, en concreto, como cuando, en un contexto especifico al que se enfrenta el agente una norma obliga ejecutar cierta acción y otra, en el mismo contexto, lo permite. De igual modo, en sentido contrario. Se trata, de una incompatibilidad funcional, antes que lógica. El tercer y último caso contenido en las ideas precedentes es aquel que se desprende del trabajo de Hamner Hill, con énfasis en el carácter funcional de las normas, permitiéndonos distinguir el caso en que una norma al colisionar frustra el objetivo pretendido por la otra o, la excluye al competir para la resolución de un caso. No incorporamos la Teoría de la Ponderación en esta sección, relativa a los conflictos entre principios, dado lo dicho en secciones precedentes y por ser estas taxonomías propuestas para sistemas de reglas, mayormente.

A continuación, como último paso del ejercicio analítico, utilizaré los

${ }^{58}$ Cfr. Martínez, cit. (n. 49), p. 87; Ausín, cit. (n. 49), p.132. 
enunciados normativos reformulados a partir de las disposiciones descritas de la Ley de EIV y las reglas concretizadas del debido proceso, para ubicarlas en los tipos de conflictos descritos. En particular, identificaremos dos conflictos normativos, esto es, el que se produce entre el principio del derecho a la prueba y la regla relativa a la limitación del acceso a la copia íntegra de la entrevista investigativa para los intervinientes en el proceso penal y, el conflicto que se produce entre el derecho a la prueba derivado del debido proceso y la regla que impide el interrogatorio directo a los niños por parte de los intervinientes en el proceso penal.

2. Tipo de conflicto entre la regla derivada del principio del debido proceso y la regla de reserva de la entrevista

Esta antinomia se produce entre la regla derivada del principio del debido proceso que hemos reformulado como: "En un proceso legal es obligatorio cautelar la producción de prueba" y la regla derivada del principio del respeto al interés superior del niño, y contenida en la Ley de EIV, que hemos reformulado como: "El Fiscal está obligado a entregar las copias de la declaración del niño distorsionadas al interviniente que lo haya solicitado". Esta última norma la hemos categorizado como prescriptiva contenedora de un mandato imperativo mediante la utilización de un modalizador deóntico equivalente a una obligación.

Así, para ubicar el conflicto en las taxonomías descritas precedentemente, ha sido necesario recurrir a la propuesta de Riccardo Guastini, relativa a la concreción de principios en reglas, a fin de que se produzca el conflicto que buscamos describir. Como ya indicamos, para GUASTINI, ${ }^{59}$ los principios son de aplicación controvertida dado que no cuentan con soluciones unívocas para los casos previstos por la norma. En efecto, GuAstinI describe como, dada la indeterminación en que son formulados los principios constitucionales, estos deben concretarse mediante su utilización como premisa de un razonamiento cuyo resultado es la creación de una regla, hasta ese momento no formulada.

Por lo tanto, dado que he descrito el derecho a la prueba como un principio del tipo directriz o norma programática, para su aplicación es necesaria la reformulación hecha. En ella, el conflicto se produce cuando

${ }^{59}$ Cfr. Guastini, cit. (n. 28), p.212. 
el agente es el Juez de Garantía, quien ha sido requerido por la defensa del imputado en causa penal, mediante una solicitud de cautela de garantías, ${ }^{60}$ dado que el fiscal del Ministerio Público le ha otorgado copias de la entrevista investigativa con una imagen y audio distorsionada, que no corresponde de forma íntegra al relato incriminatorio de la víctima. En el testimonio de un NNA puede encontrarse información incriminatoria o exculpatoria contenida en gestos, actitudes, movimientos o expresiones físicas que son captadas por la grabación de la entrevista. Sin embargo, al distorsionar el registro, dado que esa modificación está destinada a ocultar rasgos que permitan la identificación de la víctima, esta información útil puede ocultarse y pudiere presentarse el caso en que para la realización de una pericia testimonial a la defensa no le baste este registro ni el acceso limitado en dependencias del Ministerio Público. ${ }^{61}$ Por tanto, en el caso descrito, el juez tiene la regla derivada o concretizada del derecho a la prueba y debido proceso que hemos señalado. ¿Debe acceder a la solicitud de la defensa de acceso a la entrevista íntegra?

Así, dado que se trata de normas que al agente le sugieren "obligatorio entregar copias íntegras de la entrevista" y "prohibido entregar copias íntegras de la entrevista", ubico este conflicto en lo que Guastini ${ }^{62}$ considera una antinomia en abstracto, o MUNZER ${ }^{63}$ considera un conflicto directo o inmediato de normas que lógicamente son imposibles de cumplir conjuntamente, dados los modalizadores deónticos que poseen. En el mismo sentido, podría utilizar también la categoría de HAMNER Hill ${ }^{64}$ de contradicción normativa, por los mismos motivos.

\footnotetext{
${ }^{60}$ El contexto de la decisión del agente en el caso está enmarcado en la disposición del artículo 10 del Código Procesal Penal, en virtud de la cual "En cualquier etapa del procedimiento en que el juez de garantía estimare que el imputado no está en condiciones de ejercer los derechos que le otorgan las garantías judiciales consagradas en la Constitución Política, en las leyes o en los tratados internacionales ratificados por Chile y que se encuentren vigentes, adoptará de oficio o a petición de parte, las medidas necesarias para permitir dicho ejercicio".

${ }^{61}$ La norma contenida en el artículo 23 de la Ley EIV establece que la distorsión de los elementos de la videograbación que permitan la identificación de la víctima tiene como límite la afectación de la comprensión. Por tanto, otro modo de abordar la solución al caso, es el debate acerca de la efectividad de configurarse la excepción normativa incorporada en el enunciado.

${ }^{62}$ Cfr. Guastini, cit. (n. 2), p. 538.

${ }^{63}$ MunZer, cit. (n. 51), p.1144.

${ }^{64}$ Hamner Hill, cit. (n. 32), p.241.
} 
3. Tipo de conflicto entre la regla derivada del principio del debido proceso y la regla que regula el interrogatorio y contra interrogatorio del NNA

Un último conflicto que quisiera presentar es el que se produce entre el derecho a la prueba y la regla relativa al interrogatorio al niño, mediante la utilización de un intermediador. La regla extraída de la Ley de EIV la hemos reformulado del siguiente modo: Los intervinientes no dirigirán preguntas directamente al NNA. En efecto, he dicho que, vista así la norma, sería regulativa, ${ }^{65}$ prescriptiva ${ }^{66}$ y prohibitiva, ${ }^{67}$ con una formulación deóntica de modo prohibición emanada de la autoridad. Esta regla colisiona con la que hemos concretizado ${ }^{68} \mathrm{o}$ derivado del debido proceso en su vertiente derecho a la prueba, del siguiente tenor: En un proceso legal, es obligatorio cautelar el examen y contra examen de la prueba.

El conflicto en concreto se produce en el juicio oral, en el que los intervinientes quieren formular sus preguntas directamente al niño, esto es, accediendo a la prueba, al examen y contra examen de la prueba, de manera directa. Sin embargo, en virtud de la regla contenida en la Ley de EIV que ha materializado el principio de interés superior del niño como obligación de respetar en las actuaciones del proceso la protección y bienestar de este, los intervinientes solo podrán formular preguntas por intermedio de un tercero que cumple la función de intermediador. ${ }^{69} \mathrm{Se}$ trata, además, de un intermediador que está habilitado para reformular la

\footnotetext{
${ }^{65}$ Agüero-San JuAn, cit. (n. 21), p. 33.

${ }^{66}$ Moreso y Vilajosana, cit. (n. 44), p. 63

${ }^{67}$ Moreso y Vilajosana, cit. (n. 44), p. 62

${ }^{68}$ Cfr. Guastini, cit. (n. 28), p. 212.

${ }^{69}$ El conflicto presentado no debe considerarse menor o superado por el mero establecimiento de la regla de la intermediación en la declaración judicial, de acuerdo a la norma de los artículos 13 y siguientes de la Ley EIV. Por el contrario, las características del examen y contraexamen tradicional se las ha considerado un elemento básico del derecho a la confrontación de la que es titular la defensa del acusado en juicio. El derecho a confrontación ha sido descrito como un derecho fundamental para cuyo ejercicio pleno y efectivo la defensa debe estar en posición de cuestionar el contenido de la declaración del testigo de cargo (en este caso la víctima NNA); agregando aspectos omitidos; hacer precisiones, desacreditando, en definitiva, el testimonio. Cfr. DuCE, cit. (n. 25), p. 128. En un sentido similar ya había sido planteado en Baytelman, Andrés; Duce, Mauricio, Litigación Penal Juicio Oral y Prueba, Eds. Universidad Diego Portales, Santiago, 2005, p. 326. Las virtudes epistémicas del contra examen, relativas a la búsqueda de la verdad en los sistemas adversariales, ha sido abordada con dogmática y jurisprudencialmente en VIAL, Pelayo, "El derecho a confrontación con declaraciones de un juicio anulado en el marco del proceso penal”, Revista Política Criminal, 2011, Vol. 6, n 12, p. 450.
} 
pregunta en términos que le parezcan adecuados y respetuosos del niño, ${ }^{70}$ eventualmente modificando de manera relevante el contenido semántico del interrogatorio o contra interrogatorio. En el sentido de lo descrito, la Ley de EIV entrega amplias facultades al intermediador, ${ }^{71}$ sin perjuicio del control y supervisión del juez presidente del tribunal o el juez de garantía en el caso de la declaración anticipada. ${ }^{72}$

Así, la colisión normativa se produce entre una norma prohibitiva (prohibido dirigir preguntas directamente al niño) y la obligatoria de acceder a examinar y contra examinar la prueba. Por tanto, dado que una de las normas en el conflicto al que se somete el agente es prohibitiva y la otra, en el mismo supuesto de hecho es obligatoria, es posible sostener que se trata de un conflicto lógico, abstracto ${ }^{73}$ de imposibilidad de cumplimiento conjunto, siguiendo en ello a MunZer ${ }^{74}$ y a HAMner Hill, respecto de su contradicción normativa. ${ }^{75}$

\footnotetext{
${ }^{70} \mathrm{La}$ necesidad de control por parte de los intervinientes respecto de la forma en la que se examina y contraexamina la prueba (en este caso el testimonio del NNA que comparece como testigo al juicio oral) ha sido ampliamente recogido por la doctrina procesal penal chilena. Sobre el punto es posible revisar: Chaнuán, Sabas, Manual del nuevo procedimiento penal, Abeledo Perrot - Legal Publishing Chile, Santiago, 2012, p. 25 ss.; HoRvitz sobre el punto describe la confrontación como una posibilidad real de máxima refutación de la acusación y como la principal garantía de los fines de un sistema acusatorio. Cfr. Honvitz, María Inés; López, Julián, Derecho Procesal Penal Chileno, Editorial Jurídica de Chile, Santiago, 2004, p.253.

${ }^{71}$ Comisión Nacional de Coordinación del Sistema de Justicia Penal (Eds.), "Protocolo del artículo 31 letra i) de la Ley ${ }^{\circ} 21.057$, que Regula entrevistas grabadas en video y, otras medidas de resguardo a menores de edad, víctimas de delitos sexuales", Informe, Ministerio de Justicia, Santiago, 2019, 18 p., documento .pdf disponible en línea: https://www.minjusticia.gob.cl/media/2020/01/Protocolo-i.pdf (consultada: 30 de abril de 2021), p.18. De acuerdo a este documento, en caso de que el intermediario considere que una pregunta formulada por los intervinientes durante el juicio oral, pueda ser coactiva, compleja, engañosa o poco clara; o, provocar sufrimiento o una grave afectación del NNA, lo planteará al juez, quien resolverá, previo debate. En caso de ordenarse al intermediario hacer la pregunta al NNA, este la transmitirá reformulándola de acuerdo a su edad, madurez y condición psíquica. Esta falta de inmediación en la forma en la que se rinde la prueba fue motivo de debate durante la tramitación de la ley y fue consignada expresamente como una de las tensiones producidas por la Ley de EIV y el procedimiento penal. Así fue explicitado por académicos invitados al Congreso Nacional y por representantes de la Defensoría Penal Pública. Cfr. con Biblioteca del Congreso Nacional (Eds.), Historia de la Ley 21.057, disponible en https://www.bcn.cl/historiadelaley/nc/historia-de-la-ley/7481/ (consultada: 30 de abril de 2021), pp. 32; 34; 206.

${ }^{72}$ La situación está regulada en la norma contenida en el Artículo 17 de la Ley de EIV.

${ }^{73}$ Cfr. Guastini, cit. (n. 2), p. 538.

${ }^{74}$ Munzer, cit, (n. 51), p. 1144.

${ }^{75}$ Hamner Hill, cit, (n. 32), p. 239.
} 


\section{ASPECTOS A MODO DE SOLUCIÓN EN RELACIÓN A LOS CON- FLICTOS PRESENTADOS}

Como soluciones y consideraciones para terminar el análisis de los conflictos presentados, es posible señalar:

Respecto del conflicto normativo descrito entre el principio del debido proceso, como el derecho a la prueba que lo integra, y el principio de respeto al interés superior del niño, para su solución he propuesto ponderar las circunstancias concretas del caso. Ello obliga identificar los supuestos de hecho que el juez debe comparar para preferir un principio u otro. De este modo, siguiendo el ejemplo descrito, el juez deberá construir para el caso una jerarquía axiológica móvil que sirva a la solución y decisión de preminencia de un principio u otro. Esta pudiere considerar, entre otros, aspectos como:

1.- La condición de NNA y, en particular, la edad de la víctima que ha comparecido al juicio como testigo. No tendrá el mismo efecto en la ponderación si se trata de un niño, niña o adolescente, esto es, mayor o menor de catorce años.

2.- La situación actual del NNA, esto es, al momento de la actuación procesal, su disponibilidad y estado de afectación emocional, general. Cabe señalar, que no es parte de este trabajo resolver cómo constarán estas circunstancias al juez, cuestión que deberá resolver en uso de sus facultades de control, supervisión y dirección del juicio oral.

3.- Aspectos relativos al hecho motivo de la acusación, el bien jurídico implicado y la participación del NNA en sus elementos fácticos. En particular, puede considerar la información relativa al punto o ítem de prueba sobre el que recae su testimonio.

Por eso, siguiendo el caso hipotético ofrecido y siendo consistente con las normas de la Ley de EIV, el Juez pudiere preferir el interés superior del niño y, denegar la pretensión de la defensa.

Respecto de los conflictos entre reglas derivadas del debido proceso y derecho a la prueba y las reglas contenidas en la Ley de EIV, que también son, en buena medida, derivadas por el legislador del principio de interés superior del niño, he descrito que se trata de antinomias en abstracto, producidas entre normas con modalizadores deónticos que hacen incompatible el cumplimiento conjunto. Describiendo las taxonomías de Guastini, Munzer, Hamner Hill y otros receptores de esas ideas, he descrito 
por qué me parece que se trata de contradicciones normativas ineludibles, entre normas obligatorias contradictorias. Con todo, esta conclusión está determinada fuertemente por el modo en que las reglas han sido obtenidas a partir de la reformulación de los enunciados normativos presentados. En ese sentido, la solución al conflicto obligará al juez a preferir algunas de las reglas en conflicto, o justificar la utilización de una excepción para la entrega de copias íntegras, sin distorsión, pero en condiciones de razonable seguridad para el NNA.

Respecto del conflicto presentado respecto del examen y contraexamen directo, la aplicación de una regla e inaplicación de la otra considerará, estimo, el modo en que dicha nueva función se vaya desarrollando en la práctica.

Finalmente, y ahora refiriéndome a los conflictos presentados, en general, la Teoría de la Ponderación permite describir la importancia de aspectos concretos del caso, o los elementos que constituyen los supuestos de hecho que el juez (agente), debe comparar para preferir un principio u otro. En este caso, la jerarquía axiológica móvil de GuAstinI, está determinada por las condiciones ya descritas para nuestros ejemplos. Sin perjuicio de lo anterior, coincido con Moreso en que resulta altamente discutible la calificación de ALEXY de sacrificio o satisfacción leve, media o grave del principio ponderado. Esto, inevitablemente me lleva a la discusión sobre los estándares de prueba, cuestión que no es de interés en este texto y, a riesgo de confusión insalvable, es mejor no tratar.

Siguiendo esta vez a MoReso en su crítica al particularismo de Alexy, resulta clarificador entender que estos conflictos se producen en el razonamiento subsuntivo el agente. La especificación de las condiciones de aplicación de un principio, que no son otras que las circunstancias concretas del caso, como serían la edad o características del NNA, permiten la generación de una regla con un impacto práctico mayor al pretendido por AleXY, esto es, la formulación de una regla capaz de regular - por ejemplo - todos los conflictos normativos producidos por la entrega de copias de entrevistas videograbadas o interrogatorios de NNA en juicio oral, si en ellos las condiciones de aplicación del principio del derecho a la prueba o el interés superior del niño al ser subsumidos, son las mismas. 


\section{REFLEXIONES FINALES}

Muchas de las ideas presentadas abren nuevas líneas de análisis, dudas o, derechamente, frentes de problema para el rendimiento de las categorías y las normas utilizadas, sus reformulaciones o aplicaciones.

Al cierre, creo necesario volver sobre el objeto del texto. Si bien he pretendido verificar el rendimiento de las propuestas teóricas sobre antinomias en la ley sobre entrevista videograbada de niños, niñas y adolescentes, la importancia de la reflexión no deja de ser práctica. El texto legal utilizado para trabajar los conflictos normativos, es una ley largamente esperada por los operadores del sistema de justicia penal y, más aún, por organizaciones de la sociedad civil dedicadas a la protección de NNA víctimas de delitos. Más aún, ya publicada la Ley 21.057, su entrada en vigencia en todo el país es inminente y los problemas asociados a su implementación, persistentes.

Si el objetivo de la Ley de EIV ha sido la protección del interés de NNA, en alguna medida, ello ha desplazado el interés del imputado de confrontar cierta prueba de cargo, mermando, de acuerdo al caso concreto, el debido proceso que le asiste. Desde este punto surge el esquema de análisis propuesto en el trabajo.

En los próximos meses estará el texto vigente en todo el país y esquemas analíticos como estos servirán para resolver $u$ ofrecer argumentos para preferir una norma u otra. Cualquiera sea el caso, estimo, relevante que la ponderación de principios o resolución de antinomias entre reglas, debe dar cuenta de razonamientos explícitos y justificaciones controlables, al menos explicitando las consideraciones morales o axiológicas que hagan que se jerarquice una u otra norma en el caso particular.

\section{BIBLIOGRAFÍA CITADA}

\section{1) Doctrina}

Agüero-San Juan, Sebastián, "Las antinomias y sus condiciones de surgimiento. Una propuesta para los enunciados normativos", Revista de Derecho de Valdivia, 2015, Vol. 28, n 2.

AleXy, Robert, Teoría de los Derechos Fundamentales, Centro de Estudios Constitucionales, Madrid, 2002.

Atienza, Manuel; Ruiz Manero, Juan, Las piezas del Derecho, Editorial 
Ariel, Barcelona, 1996.

Ausín, Txetxum, Entre la lógica y el Derecho. Paradojas y conflictos constitucionales, Plaza y Valdés Editores, México D.F., 2005.

Baytelman, Andrés; Duce, Mauricio, Litigación Penal Juicio Oral y Prueba, Eds. Universidad Diego Portales, Santiago, 2005.

Biblioteca del Congreso Nacional (Eds.), Historia de la Ley 21.057, https:/www.bcn.cl/historiadelaley/nc/historia-de-la-ley/7481/ (consultada: 30 de abril de 2021).

Bordalí, Andrés, Justicia Constitucional y derechos fundamentales, Lexis Nexis, Santiago, 2006.

Carnelutti, Francesco, La prueba civil, Depalma, Buenos Aires, 2000, $2^{\mathrm{a}}$ ed.

Comisión Nacional de Coordinación del Sistema de Justicia Penal (Eds.), "Protocolo del artículo 31 letrai) de la Ley n²1.057, que Regula entrevistas grabadas en video $y$, otras medidas de resguardo a menores de edad, víctimas de delitos sexuales", Informe, Ministerio de Justicia, Santiago, 2019, 18 p., documento .pdf disponible en línea: https://www.minjusticia.gob.cl/media/2020/01/Protocolo-i. pdf (consultada: 30 de abril de 2021).

Couture, Eduardo, Fundamentos del Derecho Procesal Civil, B. de F., Montevideo - Buenos Aires, 2005, $4^{\mathrm{a}}$ ed. (reimpresión).

Chahuán, Sabas, Manual del nuevo procedimiento penal, Abeledo Perrot Legal Publishing Chile, Santiago, 2012.

DucE, Mauricio, "Derecho a la confrontación y uso de declaraciones emitidas en un juicio previo anulado", Revista Política Criminal, 2014. Vol. 9, n 17.

FERrER, Jordi. La valoración racional de la prueba, Marcial Pons, Madrid, 2007.

García, Sergio. "El debido proceso en la jurisprudencia de la Corte Interamericana de derechos humanos", en TAVOLARI, Raúl (coord.), Derecho Procesal Contemporáneo. Ponencias de las XII Jornadas Iberoamericanas de Derecho Procesal. Thomson Reuters - Punto Lex, Santiago, 2010, T. I.

Guastini, Riccardo. Interpretar y Argumentar, Centro de Estudios Políticos y Constitucionales, Madrid, 2014.

Guastini, Riccardo. La Sintaxis del Derecho, Marcial Pons. Madrid. 2016.

Guastini, Riccardo, Las Fuentes del Derecho. Fundamentos Teóricos, Raguel Editores, Lima, 2016.

Hamner Hill, H. "A functional taxonomy of normative conflict", Law and Philosophy Review, 1987, Vol. 6, pp. 227-247, https://doi.org/10.1007/BF00145430 (consultada: 13 de abril 2020).

Horvitz, María Inés; LóPez, Julián, Derecho Procesal Penal Chileno, Editorial Jurídica de Chile, Santiago, 2004.

López, Julián, "Debido proceso en Chile. Hacia un principio generador de reglas”, en: Bordalí, A. (Coord.), Justicia constitucional y derechos fundamentales, 
LexisNexis, Santiago, 2006, pp. 181-207.

Martínez, David, Conflictos Constitucionales. Ponderación e Indeterminación Normativa, Marcial Pons, Madrid, 2007.

Moreso, José Juan, La Constitución, Un Modelo Para Armar, Marcial Pons, Madrid, 2009.

Moreso, José Juan; Vilajosana, Josep María, Introducción a la teoría del derecho, Marcial Pons, Madrid, 2014.

Munzer, Stephen, "Validity and legal conflicts", Yale Law Review, 1973, No 82.

VIAL, Pelayo, "El derecho a confrontación con declaraciones de un juicio anulado en el marco del proceso penal", Revista Política Criminal, 2011, Vol. 6, n 12.

\section{2) Normativa}

Constitución Política de la República de Chile (1980).

Decreto No 830 de 1990, que aprueba la Convención de Derechos del Niño.

Decreto No 873 de 1991, que aprueba la Convención Americana de Derechos Humanos.

Ley N ${ }^{\circ} 19.696$ de 2000, que aprueba el Código Procesal Penal.

Ley $\mathrm{N}^{\mathrm{o}} 21.057$ de 2018, que regula entrevistas grabadas en video y, otras medidas de resguardo a menores de edad, víctimas de delitos sexuales.

\section{3) Jurisprudencia}

Tribunal Constitucional, 7 de septiembre de 2010, Rol N ${ }^{\circ}$ 1411- 2010.

Tribunal Constitucional, 7 de julio de 2011, Rol No 1838- 2011.

Corte Suprema, 7 de octubre de 2004, Rol No 3304-2004

Corte Suprema, 14 de septiembre de 2005, Rol No 3666-2005

Corte Suprema, 17 de abril de 2006, Rol No 1383-2006

Corte Suprema, 27 de octubre de 2005, Rol No 5052-2005

Corte de Apelaciones de Antofagasta, Rol N $166 / 2021$

Corte Interamericana de DDHH, 23 de noviembre de 2009, Radilla Pacheco vs. México

Corte Interamericana de DDHH, Opinión Consultiva $\mathrm{N}^{\mathrm{o}} 17,28$ de agosto de 2002 (disponible en http://www.corteidh.or.cr/docs/opiniones/seriea_17_esp.pdf, consulta 13 de abril 2020). 